\title{
Highly integrated Electric Drives for Automotive Application
}

\author{
Michael Schier, Frank Rinderknecht \\ German Aerospace Center \\ Pfaffenwaldring 38-40 \\ 70569 Stuttgart, Germany \\ Email: michael.schier@dlr.de, frank.rinderknecht@dlr.de
}

\author{
N. Satheesh Kumar \\ Nanyang Technological University \\ Block S2 - B3a - 01, 50 Nanyang Avenue, \\ Singapore 639798 \\ Email: ns0001ar@e.ntu.edu.sg
}

\begin{abstract}
Aerospace development needs an optimum in weight and volume reduction. In addition there is a high research potential on vehicle energy concepts and alternative energy converters by using synergies from aerospace research [1]. The understanding of the system behavior leads to the development of several concepts of electric drives which combine more than one function in a single technical component. The paper describes three examples of highly integrated electric drive concepts which can be used in next generation cars. The concepts are partly based on international cooperation and also on individual investigation work.
\end{abstract}

Keywords-highly integrated drive; free piston linear generator; wheel hub motor; air conditioning compressor; automotive application; electric machine; permanent magnet synchronous machine; thermal management; next generation car.

\section{INTRODUCTION}

Regarding the development of electric vehicles of next generation completely new starting points for the design of the structure as well as the drive train are given. Individual solutions for individual energy converters or auxiliary units are known today. But the interplay of many auxiliaries represents a particular challenge. Standing in front of the development of a completely new vehicle concept, it is possible to try to optimize the weight or efficiency of the total system from the beginning on. Same conditions exist often in the aerospace industry. It stands to reason, therefore, to use or combine technologies from the aerospace field and from the traffic branch. Examples are the thermoelectric generators, the lightweight construction or the usage of fuel cells tried and tested in the field of aerospace research [1].

In the field of energy conversion one is always looking for efficient solutions. Electrical energy has an important place due to its high exergy. Nevertheless in the vehicle other forms of energy such as heat or mechanical energy (usually transmitted through rotating axes) are required.

Regarding a conventional drive train with an internal combustion engine, there are a variety of solutions to integrate ancillaries like starter, dynamo, air compressor, water pump, oil pump, power steering pump, camshaft and crankshaft, driven with belts, gears, brakes and clutches, tension and idler pulleys, belt tensioning springs etc. They all have their special design issues like power demand, speed behavior, individual power losses, vibration and noise behavior etc. Nowadays there are also a number of electric drives in a car, the number may be up to 100 . It raises the question of how the still needed decentralized drives can be useful combined in future vehicles. The scope of application of electric drives can be increased significantly here. Electric motors are more than capable of driving a shaft. In addition, the thermal design is sizeand thus cost determinative in electrical energy converters. Integrated solutions save components and thus costs, if they are independent development solutions where serial parts produced with high volumes not already exist. Under these circumstances, it is natural to look to future meaningful integration projects. Integrated starter generators have historically been a good example of how hard it is to replace series parts manufactured with mass production methods. Even today, two separate electrical machines are used, unless the electric machine can also be used for boosting and driving in low electrified hybrid vehicles, then the battery is designed correspondingly large.

In the following paper three highly integrated power converters are described which can be used in future road vehicles. The first consists of a combination of an airconditioning compressor and a drive motor and can provide electrical energy, mechanical and thermal energy. The second, a free piston linear generator, converts chemically bounded energy from different liquid or gaseous fuels into electrical energy for the propulsion of vehicles. The third energy converter is a wheel hub motor, 
which was designed with an integrated gearbox and a clutch for autonomous taxiing and landing of a passenger aircraft. In principle it can also be used to power road vehicles. Based on the presented examples, the requirements and the procedure for the integration of the components as well as first results are explained. The scope of the paper is to show how to get experience in combining different technological competencies to prepare the way for increasing the efficiency of future vehicles.

\section{INTEGRATION OF AN AIR CONDITIONING COMPRESSOR INTO THE DRIVE MOTOR}

\section{A. Requirements}

A small electric urban vehicle is driving in the city with a speed of about $60 \mathrm{~km} / \mathrm{h}$ while it must also reach speeds of $120 \mathrm{~km} / \mathrm{h}$ for the extra-urban journeys. The electric motor for driving the vehicle is operated with the highest possible speed so he gets small. With a drive power of $20 \mathrm{~kW}$, one can assume a maximum speed of 12.000 $1 / \mathrm{min}$. In the city area a speed of $6.0001 / \mathrm{min}$ is expected. During braking events the electric motor will work with speeds between 6.000 and zero $1 / \mathrm{min}$.

An air conditioning compressor is operated with a maximum speed of about $3.0001 / \mathrm{min}$ and requires a driving power of about $4 \mathrm{~kW}$.

The electric drive motor for the air conditioning compressor is about half the size, if it generates the necessary power at twice the speed. For this he needs a transmission. Both units must not be more expensive than one big motor with double of the size.

If the air conditioning compressor is directly coupled to the drive shaft of the vehicle during the braking phase, he can lead direct a portion of the kinetic energy of the vehicle to the drive side of the compressor, without further energy conversion: without intermediate storage in the battery and without further conversion via converters or electric motors.

Out of these interests there is the idea to integrate the air conditioning compressor into the drive motor to couple it directly to the drive shaft. By integrating the two motors in one common casing parts can be saved, and overall efficiency including the thermal management can be increased. In addition there is the chance to operate the two electric motors in their respective best efficiency point. This concept is called the 2 in 1 motor [2, 3].

\section{B. Implementation}

The drive motor is directly connected to the wheels of the vehicle, see figure 1 . In this figure the drive motor is a permanent magnet synchronous machine. It is located on the right side and working on a central shaft which leads the torque to the left side of the housing. A second motor to drive the compressor is located on a concentric shaft and can be coupled to the drive motor over an electromagnetic clutch. On the one hand it is possible to drive the compressor separately when the vehicle stands still and on the other hand the compressor can be driven by the wheels in recuperation mode. By using two motors for driving the vehicle both motors can operate in their best operation points to increase the total efficiency of the drive. In this case the compressor suction and pressure port can be short cut if it is not needed.

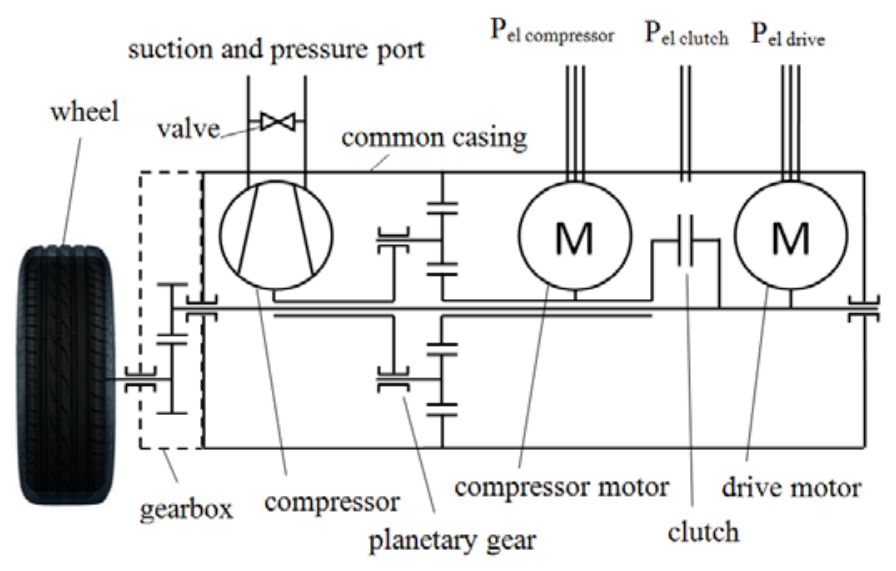

Fig. 1: Concept of the 2 in 1 electrical drive as a transaxle architecture

Figure 2 shows the design of the 2 in 1 electric drive, where the air conditioning compressor is integrated in the drive motor according to the concept in figure 1 . The gear box on the left side of figure 1 is part of the vehicle and reduces the high speed of the motor to the wheel or vehicle speed.

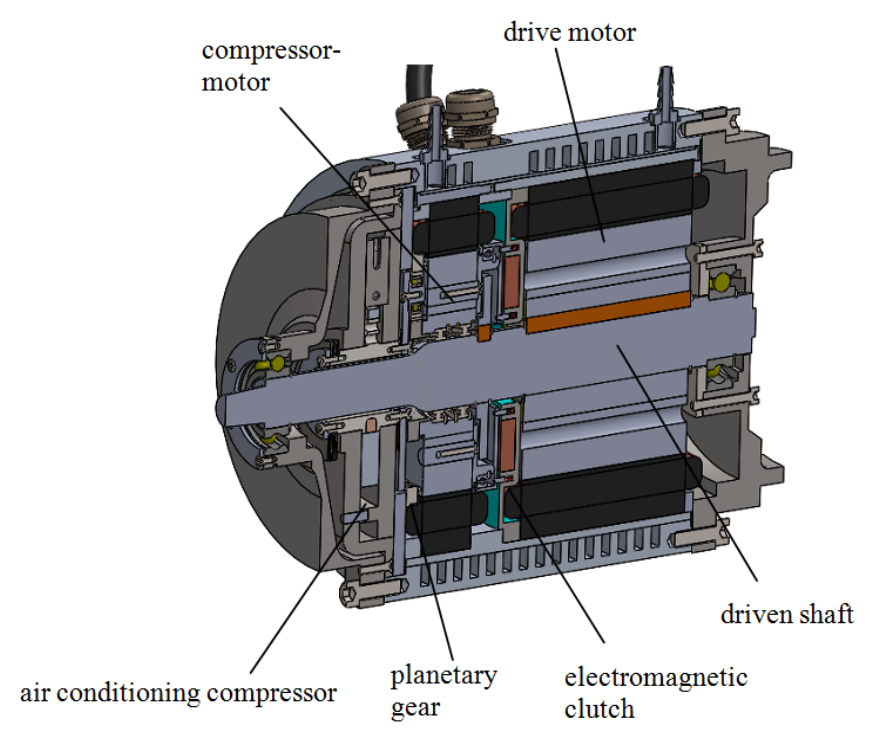

Fig. 2: Design of the 2 in 1 motor 
The air conditioning compressor is a swing vane compressor with a small axial size. It is driven by the compressor motor over an additional planetary gear. The complete system is cooled by a water jacket.

\section{Results}

Figure 3 shows the 2 in 1 motor on the test bench. The architecture of the test bench makes it possible to drive the compressor by the load machine, by its own compressor motor, but also braking or drive the drive motor by using the load machine. The first tests were related to the leakage behavior of the compressor.

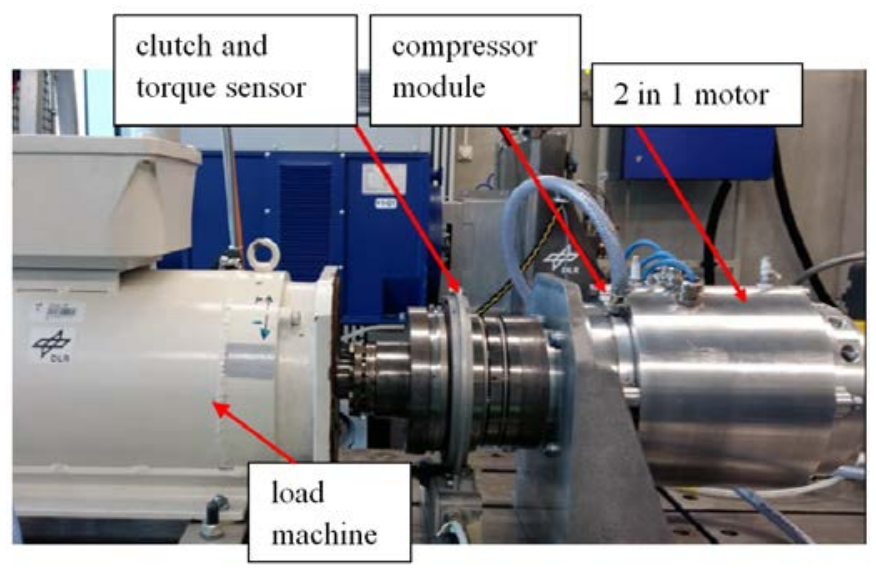

Fig. 3: 2 in 1 motor on the test bench

Following the first static leakage tests, it was of interest to investigate the key leakage paths that are contributing to measured leakage flowrate. As such, a $360^{\circ}$ protractor was attached to the crankshaft and the shaft was rotated one complete revolution in equal increments. The leakage flowrate was measured at discreet crankshaft angles and the findings are normalized and plotted in figure 4 .

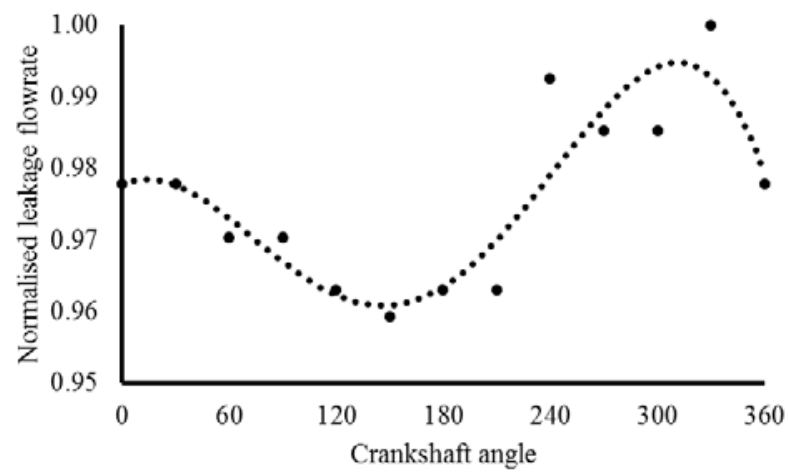

Fig. 4: 2 in 1 motor on the test bench

Analysing the plot shown in figure 4, the leakage flowrate appears to be a weak function of the crankshaft angle as the data points have a mean value of 0.98 and variance of 0.00145 . This data conveys that much of the pressurised air entering the discharge chamber leaks to the atmosphere through the gap between the cylinder circumferentially face.

\section{INTEGRATION OF A LINEAR ELECTRIC MACHINE INTO A LINEAR COMBUSTION ENGINE}

\section{A. Requirements}

The range of electric vehicles continues to lag compared to vehicles which are powered with an internal combustion engine, since the energy density of the accompanying electrical storage is smaller than the energy density of liquid fuels. To increase the range of vehicles which are used in interurban areas today range extenders are used, which are yet again powered by fossil fuels.

The overall efficiency of the powertrain shall be increased. In internal combustion engines it is still possible by a variable control of the stroke or the compression. For this the forced control of the piston movement by the crankshaft must be dispensed.

The combination of these requirements leads to the idea to develop an internal combustion engine without crankshaft, whose compression ratio or stroke is adjustable and is designed exclusively for the provision of electric power. The electric motor is integrated here and will not perform any rotational movement, but a linear movement. It is called the free piston linear generator.

\section{B. Implementation Scheme}

The free piston linear generator (FPLG) is a good example for high integrated energy converters. It's implemented by the German Aerospace Center (DLR) as a free piston combustion engine for the conversion of chemically stored energy into electric energy [4]. The structure of the free piston linear generator consists of three different subsystems: combustion unit, linear generator and gas spring, as shown in Fig. 4. The energy stored in the fuel is converted by a two-stroke internal combustion cycle in the combustion unit. The linear generator consists of a mover with permanent magnets and windings fixed in the housing, which form the stator. In combination with a compact design, the FPLG qualifies for the use as a range extender in hybrid cars. Due to the mass forces which result from the oscillating movement of the piston unit within free piston engines, the development at the DLR aims for a system with two opposite pistons. With an appropriate synchronization of the piston units, this setup allows a 
complete compensation of all mass forces. Due to a higher thermal efficiency and advantages at the synchronization of the two piston units, the DLR is developing a FPLG-system with a central combustion chamber. This arrangement is also the basis for the design of future concepts. By controling the pressure and the way of the piston individually the FPLG is able to use different fuels. The power output can be adapted by the variation of the compression. The operation frequency is constant. In this way every component of the system can be optimized for exactly one frequency.

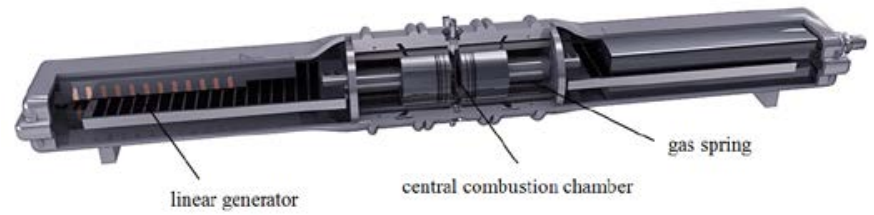

Fig. 5: Design of the free piston linear generator

\section{Results}

Figure 6 shows a FPLG with single combustion chamber as it is assembled on the test bench. Inlet and outlet valves of the combustion chamber are controlled by electromagnetic valves. The movement of the piston can be simulated by a hydraulic actuator.

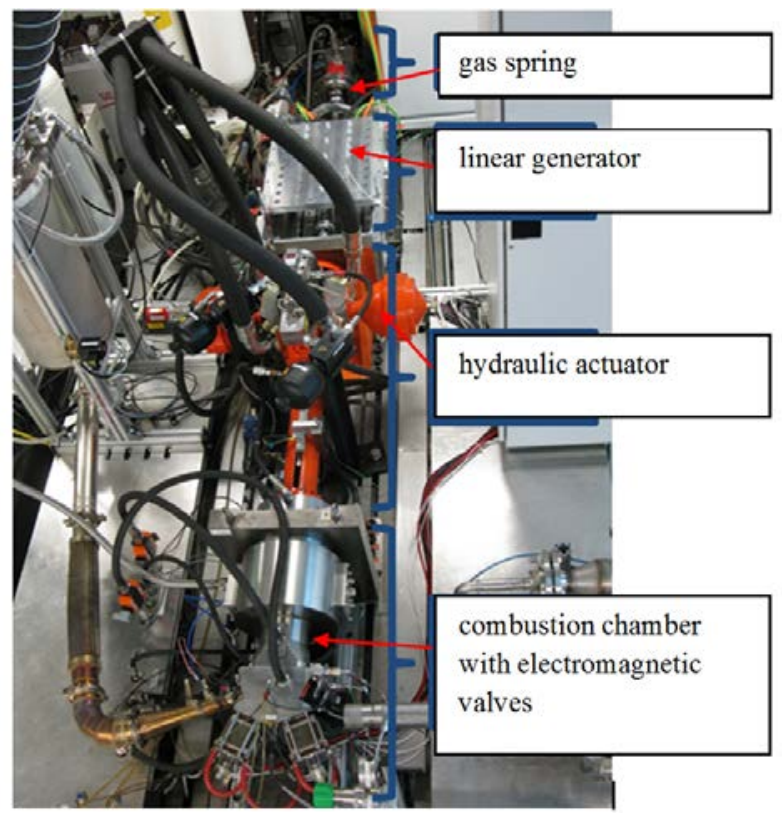

Fig. 6: Free piston linear generator on the test bench

This test bench shows the complexity of such a high integrated system. The test bench for new FPLG with central combustion chamber will be implemented during the next month.
In figure 7 the measurement based calculated efficiency of a linear generator for a single combustion chamber system and at different operating frequencies is shown.

A completely new system, based on the central combustion chamber (figure 5), is currently under development. In comparison to the established single piston system, the entire setup is new, including the gas spring, the linear generator, the central combustion chamber and several more components. During the year 2016 first measuring results demonstrating the potential of this high integrated energy converter are expected.

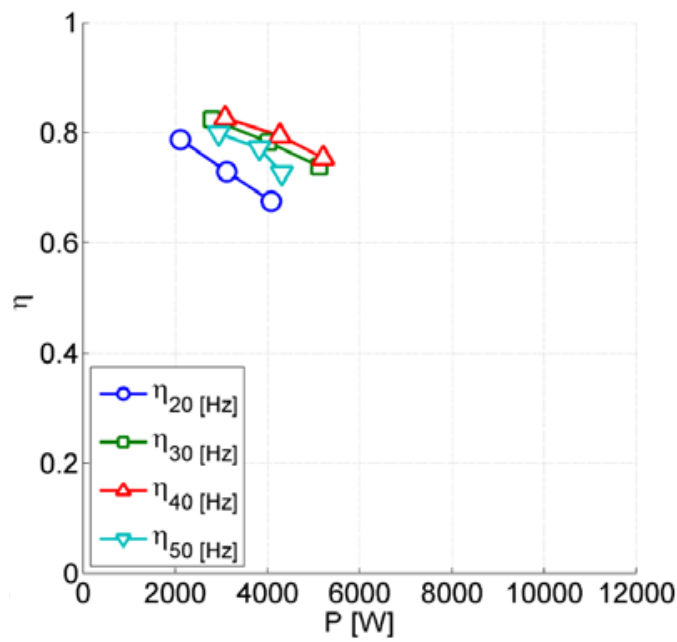

Fig. 7: Efficiency of a cylindrical linear generator

IV. INTEGRATION OF A GEAR AND A CLUTCH INTO A WHEEL HUB MOTOR

\section{A. Requirements}

In the field of aviation there were the requirements for taxiing and electrically driven passenger planes at about $25 \mathrm{~km} / \mathrm{h}$ with a torque of $11 \mathrm{kNm}$ and to accelerate the wheels towards the landing speed of about $250 \mathrm{~km} / \mathrm{h}$ to minimize the tire wear during landing. The electric energy supply will be realized with a fuel cell system which provides electricity, heat, water and oxygendepleted air to fill the fuel tanks.

\section{B. Implementation}

The special design includes the electric machine and a switchable gear with a high grade of integration [5]. In figure 8 the concept of the wheel hub drive is shown. If clutch one is closed and clutch two is open, the electric machine works directly to the wheel without any gear ratio. If clutch two is closed and clutch one is open, the rotor of the electric machine drives the wheel with a gear ration of 1:12. 


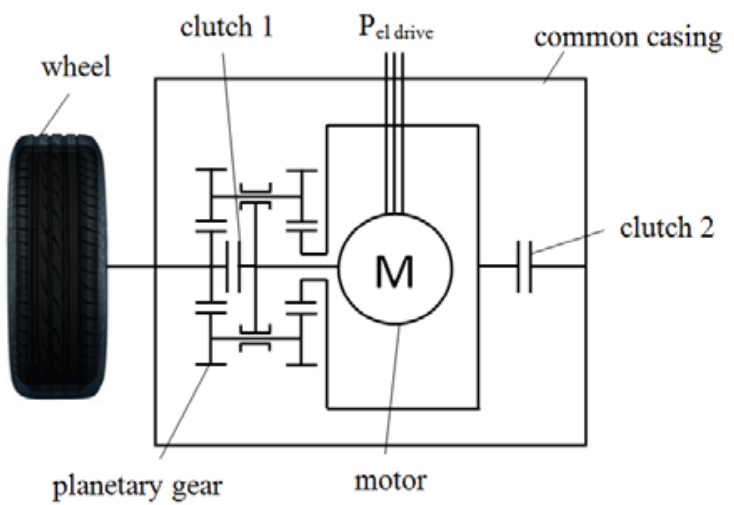

Fig. 8: Concept of the wheel hub drive where the rotor of the electric machine is the planetary carrier of the gear

Figure 9 shows the design of the wheel hub motor. The limited space inside of the original wheel does not allow the integration of an electrical machine (brown and orange colored parts in figure 9), judging from liquidcooled rotary machine specific forces of about $4 \mathrm{~N} / \mathrm{cm}^{2}$. Therefore, it is necessary to use a gear (blue and magenta colored parts) that is an integral part of the electric machine, of course, on the condition of the low weight. The electric machine is a permanent magnet synchronous machine and is based on considerations from the automotive sector. The gearbox (combination of the yellow part with the rim and the housing) provides the ability to switch three gear stages, a free wheel function to protect the electric motor with respect to high speeds, a direct transmission for acceleration of the wheel of an aircraft on landing speed and a translation stage with a ratio of 1:12 for taxiing on ground. The electric machine and the transmission with three selectable gear stages are placed within the rim. The rotor of the electric machine is indentical with the planetary carrier of the gear. Both components are as small as possible.

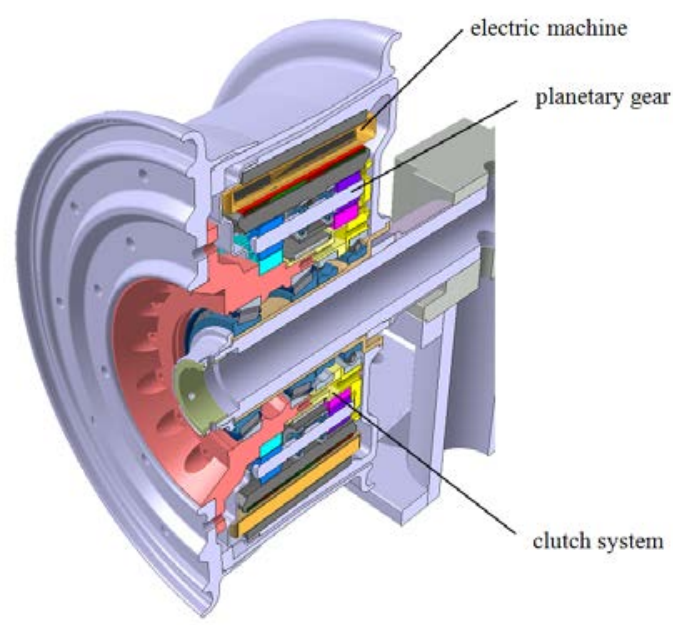

Fig. 9: Design of the wheel hub motor

\section{Results}

Two electric machines were tested on the test bench as shown in figure 10 . One is coupled to the load machine over a clutch with torque and speed meter and an additional gear box. It can be measured directly with the internal gear ratio of 1 or with the internal gear ratio of 12. The second motor can be measured in idle mode on this test bench.

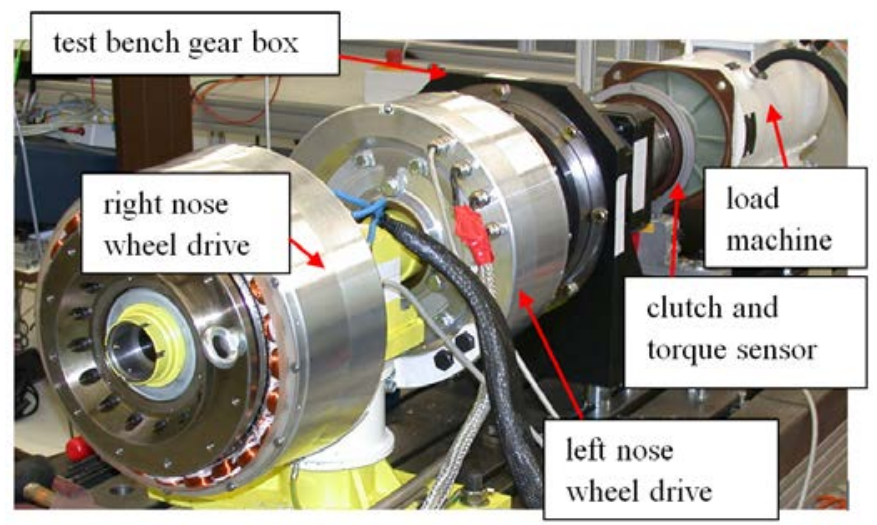

Fig. 10: Wheel hub motor on the test bench

In figure 11 the torque of one motor at a speed of $50 \mathrm{rpm}$ is shown, as it was measured on the motor test bench, working against the second electric load machine. A torque up to $2.5 \mathrm{kNm}$ was reached within the acceptable temperature range and while the motor was fed by a given inverter. The motor can be overloaded to the factor 2 for short time to reach the maximal torque of $5 \mathrm{kNm}$. The complete system was installed within a 15” rim.

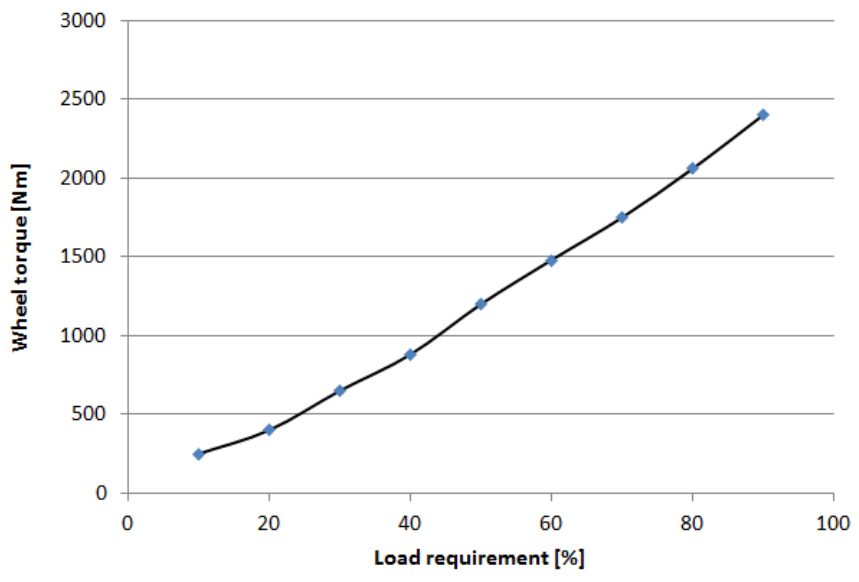

Fig. 11: Measured torque of one wheel hub motor [4]

\section{PeRsPective}

Other approaches for the integration of additional power units into the electric motor are the integration of 
the power electronics and the cooling of the winding of the electrical machine with the oil of the gear box. Hereby, the thermal resistance of the electrical machine can be reduced to half in comparison with a water jacket cooled machine, resulting in a significantly higher power density [6].

\section{CONCLUSION}

The paper proposes three novel design solutions of electric drives geared towards improving the overall operating efficiency of electric vehicles by integrating several functions into one component and saving weight. In addition to improved efficiency, the integrated units have numerous other advantages such as increased reliability, compact design and cost saving. Next generation cars will operate with several fuels or electricity, with size optimized drive train components and an innovative energy management. One example of a next generation vehicle concept is shown in figure 12, where the three components described in this paper are parts of the drive train. They can be combined by using a modular energy architecture. The range of this car can be extended by using the free piston linear generator, air conditioning is done by the 2 in 1 motor and 4 wheel drive capability is supported by two additional wheel hub motors.

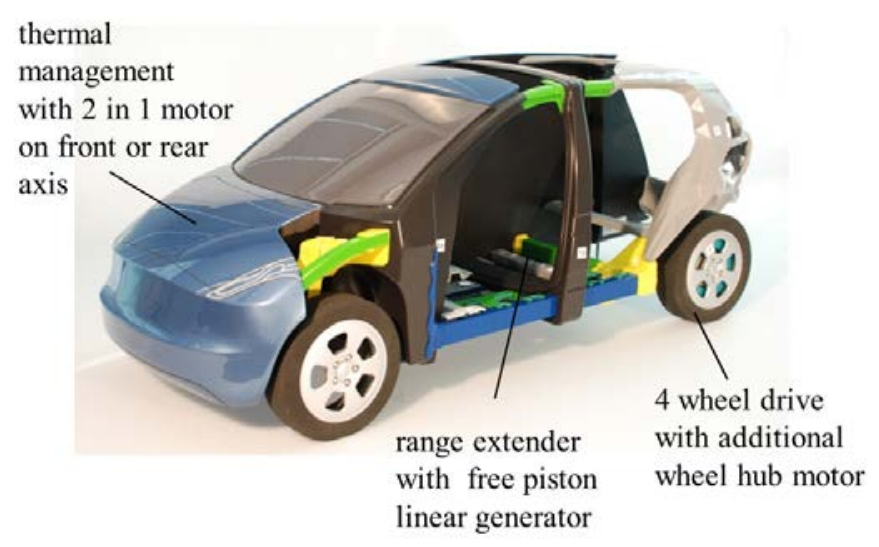

Fig. 12: Example of a vehicle concept with highly integrated electric drives

\section{ACKNOWLEDGMENT}

The authors would like to thank the following project partners:

The 2 in 1 motor is based on an international cooperation project between DLR Institute of Vehicle Concepts and the Nanyang Technological University in Singapore.

The DLR Institute of Combustion Technology is partner in investigating the free piston linear generator combustion processes.

The DLR Institute of Technical Thermodynamics is project leader in aviation fuel cell projects.

The authors also would like to thank the organizers of the EVER conferences in Monaco by providing a basic scientific platform for ecological vehicles.

\section{REFERENCES}

[1] M. Schier and F. Rinderknecht, Innovation Examples for Ecological Vehicles based on Aerospace Research, International Conference on Ecological Vehicles and Renewable Energies (EVER 13), Monte Carlo, Monaco, 27.-30. March 2013.

[2] S. Kumar and M. Schier, Increasing Efficiency of Ecological Vehicles by integrating Auxiliary Units directly to the driven Shaft, Ninth International Conference on Electric Vehicles and Renewable Energies (EVER 14), Monte Carlo, Monaco, 25.-27. March 2014.

[3] M. Schier and S. Kumar, Design of a 2 in 1 Motor to increase the Efficiency of Electric Vehicles, Tenth International Conference on Electric Vehicles and Renewable Energies (EVER 15), Monte Carlo, Monaco, 31. March - 02. April 2015.

[4] S. Schneider and F. Rinderknecht and H. E. Friedrich, Design of Future Concepts and Variants of the Free Piston Linear Generator, Ninth International Conference on Ecological Vehicles and Renewable Energies (EVER 14), Monte Carlo, Monaco, 25.-27. March 2014.

[5] M. Schier and F. Rinderknecht and A. Brinner and H. Hellstern, High integrated Electric Machine for Aircraft Autonomous Taxiing, International Conference on Electric Vehicles and Renewable Energies (EVER 11), Monte Carlo, Monaco, 31. March - 03. April 2011.

[6] Z. Liu and T. Winter and M. Schier, Comparison of Thermal Performance between Direct Coil Cooling and Water Jacket Cooling for Electric Traction Motor based on Lumped Parameter Thermal Network and Experimentation, Electric Vehicle Symposium EVS28, Kintex, Korea, 03.-06. May 2015. 